\title{
Identification and mapping of ancient pigments in a Roman Egyptian funerary portrait by application of reflectance and luminescence imaging spectroscopy
}

\author{
Roxanne Radpour ${ }^{1,3^{*}}$, Glenn A. Gates ${ }^{2}$, loanna Kakoulli and John K. Delaney ${ }^{3}$
}

\begin{abstract}
Imaging spectroscopy (IS) is an important tool in the comprehensive technical analysis required of archaeological paintings. The complexity of pigment mixtures, diverse artistic practices and painting technologies, and the oftenfragile and weathered nature of these objects render macroscale, non-invasive chemical mapping an essential component of the analytical protocol. Furthermore, the use of pigments such as Egyptian blue and madder lake, featuring diagnostic photoluminescence emission, provides motivation to perform photoluminescence mapping on the macroscale. This work demonstrates and advances new applications of dual-mode imaging spectroscopy and data analysis approaches for ancient painting. Both reflectance (RIS) and luminescence (LIS) modes were utilized for the study of a Roman Egyptian funerary portrait from second century CE Egypt. The first derivative of the RIS image cube was analyzed and found to significantly improve materials separation, identification, and the extent of mapping. Egyptian blue and madder lake were mapped across a decorated surface using their luminescence spectral signatures in the region of 540-1000 nm as endmembers in LIS analyses. Linear unmixing of the LIS endmembers and subsequent derivative analyses resulted in an improved separation and mapping of the luminescence pigments. RIS and LIS studies, combined with complementary, single-spot collection elemental and molecular spectroscopy, were able to successfully characterize the portrait's painting materials and binding media used by the ancient artist, providing key insight into their material use, stylistic practices, and technological choices.
\end{abstract}

Keywords: Imaging spectroscopy, Egyptian blue, Ancient pigments, Luminescence mapping, Funerary portraits, Derivative analysis

\section{Introduction}

Archaeological panel paintings and polychrome monuments and objects, such as decorated ceramics, painted facades, and sculptures, are artifacts of artistic and anthropological value. The study of these artifacts, in particular the materials used to construct them, help provide insight into sources of these materials, the trade routes

\footnotetext{
*Correspondence: radpour@ucla.edu

${ }^{1}$ Materials Science \& Engineering, University of California, Los Angeles, Los Angeles, USA

Full list of author information is available at the end of the article
}

used, and the development and transfer of technological methods among craftsmen. The study of their artistic form also provides information about the patrons for whom they were made [1-7].

Painted archaeological artifacts from antiquity are complex and difficult to analyze. They are decorated with various natural and synthetic colorants, applied purely, mixed and/or layered over one another, to produce distinct optical effects [8-10]. Even with a limited number of pigments, because of the skillful hand of the artist, a wide range of hues could be created.
Springer Open

(c) The Author(s) 2022. Open Access This article is licensed under a Creative Commons Attribution 4.0 International License, which permits use, sharing, adaptation, distribution and reproduction in any medium or format, as long as you give appropriate credit to the original author(s) and the source, provide a link to the Creative Commons licence, and indicate if changes were made. The images or other third party material in this article are included in the article's Creative Commons licence, unless indicated otherwise in a credit line to the material. If material is not included in the article's Creative Commons licence and your intended use is not permitted by statutory regulation or exceeds the permitted use, you will need to obtain permission directly from the copyright holder. To view a copy of this licence, visit http://creativecommons.org/licenses/by/4.0/. The Creative Commons Public Domain Dedication waiver (http://creativeco mmons.org/publicdomain/zero/1.0/) applies to the data made available in this article, unless otherwise stated in a credit line to the data. 
Difficulties encountered in studying the materials in ancient painting originate from natural aging and deterioration due to adverse environmental and anthropogenic effects. Using spectroscopic tools such as Raman spectroscopy and reflectance, luminescence, or X-ray fluorescence (XRF) spectroscopy, in 2D spatial scanning configurations, can mitigate challenges posed by degradation products that conceal original decoration and help rebuild a pictorial scheme when much of the original material seems to have been lost over time. For example, painted decorative features that have been visually obscured by mineral crusts that have deposited onto the paint surface over time can be rendered visible by imaging at wavelengths at which the crust material is transparent. By performing 2D spatial spectroscopic analyses, information can be recovered on the distribution of original artist materials, degradation products and possible restoration materials. Such information can help understand artist working methods and the state of conservation of the artwork, as well as a sense of the original extent and appearance of the painting [11-16].

The most accessible pigments available to ancient artists for painting included mined minerals, such as ochres (pigments containing ferric oxides/oxyhydroxides, clay, and sand), e.g. hematite $\left(\mathrm{Fe}_{2} \mathrm{O}_{3}\right)$-rich red ochre and goethite $(\mathrm{FeO}(\mathrm{OH}))$-rich yellow ochre, malachite $\left(\mathrm{Cu}_{2} \mathrm{CO}_{3}(\mathrm{OH})_{2}\right)$, green earth (celadonite, $\left.\left(\mathrm{K}\left(\mathrm{Mg}, \mathrm{Fe}^{2+}\right)\left(\mathrm{Fe}^{3+}, \mathrm{Al}\right)\left[\mathrm{Si}_{4} \mathrm{O}_{10}\right](\mathrm{OH})_{2}\right)\right)$, jarosite $\left((\mathrm{K}, \mathrm{Na}) \mathrm{Fe}_{3}^{3+}(\mathrm{OH})_{6}\left(\mathrm{SO}_{4}\right)_{2}\right)$, azurite $\left(\mathrm{Cu}_{3}\left(\mathrm{CO}_{3}\right)_{2}(\mathrm{OH})_{2}\right)$, pyrolusite $\left(\mathrm{MnO}_{2}\right)$ and calcium carbonate $\left(\mathrm{CaCO}_{3}\right)[10$, 17-19]. Other readily available pigments (both inorganic and organic) were synthesized using existing technology. These include: Egyptian blue $\left(\mathrm{CaCuSi}_{4} \mathrm{O}_{10}\right)$, a high-fired vitreous compound, madder lake, an organicinorganic hybrid pigment derived from madder root, lead $(\mathrm{Pb})$ white $\left(\mathrm{PbCO}_{3}\right.$ - cerussite, the natural form, or $\mathrm{PbCO}_{3}+2 \mathrm{PbCO}_{3} \cdot \mathrm{Pb}(\mathrm{OH})_{2}$ - cerussite + hydrocerussite, the synthetic form), red lead (or minium, $\mathrm{Pb}_{3} \mathrm{O}_{4}$ ), and indigo blue [8, 20-25].

In ancient painting, combinations of white (calcium carbonate or lead white [17, 25-27]) and black (carbon black or pyrolusite) pigments were mixed with different amounts of red and yellow pigments to create naturalistic flesh tones $[28,29]$. Black pigments were primarily used to delineate figures, to create chiaroscuro (shading) and in mixtures with other pigments to create darker tonal variations [30]. All of these pigments have distinct visible or infrared absorption features that make them distinguishable from one another using diffuse reflectance spectroscopy.

Certain pigments such as Egyptian blue and madder lake have photoluminescence properties that provides for a complementary method to reflectance spectroscopy to identify and map them. Egyptian blue has an absorbance band at $630 \mathrm{~nm}$ and a near-infrared (NIR) luminescence band centered at $910 \mathrm{~nm}$ [31]. This NIR emission band has been used as a characteristic marker to identify and map Egyptian blue in ancient painting, often done using visible-induced NIR luminescence photography $[32,33]$. Ancient madder lake rich in purpurin [34, 35] has absorption features centered at $\sim 510$ and 545 $\mathrm{nm}$ and has a fluorescence band centered at $605 \mathrm{~nm}$ [36, 37], which can be imaged using blue/green excitation to record the red fluorescence [38].

This paper demonstrates how dual-mode imaging spectroscopy can provide insightful material maps of ancient paintings. Imaging spectroscopy involves the collection of hundreds of images in narrow and adjacent spectral bands, stacked to produce 3D image cubes (2D spatial and 1D spectral) of a scene [39]. In the first imaging mode, reflectance imaging spectroscopy (RIS), image cubes have diffuse reflectance spectra which contain characteristic electronic and vibrational features that provide molecular information useful to identity the artist materials present. Luminescence imaging spectroscopy (LIS), the second modality, uses the same instrumentation. The diffuse broadband illumination source is replaced by a filtered excitation light to induce photoluminescence [16]. Here the spectral data consists of luminescence spectra which also can be used to help identify luminescent pigments. The large number of spectra in each of these 3D image cubes are reduced to a limited number of characteristic spectra called endmembers that represent the majority of the spectra in the image cubes. This is done using multivariate statistical algorithms adapted from remote sensing [40].

RIS and LIS have been proven successful in the analysis of fine art paintings [13-15] and manuscripts [11, 12] in identifying artist materials. Few papers on the applications of RIS for archaeological objects exist though they have yielded promising results [41-44]. LIS offers a promising approach for the identification and robust chemical mapping of luminescent pigments in complex paintings in spite of the challenges of strong luminescence absorption which can result in distortions of the shape of emission spectra. This can lead to confusion as to the number of luminescence species in the painting and presents difficulties in identifying them. For example, as the optical density (concentration $\times$ thickness) of madder lake is increased, the color becomes saturated and the emission shape distorts and the peak maximum shifts along the wavelengths. After correction, the emission shape is restored and the maximum remains constant. A methodology to mitigate these effects in LIS using approaches developed for point measurements has been demonstrated $[45,46]$. 
LIS is a new analytical protocol for the study of ancient paintings. In one multimodal imaging study, a single luminescent pigment, madder lake, was successfully identified and mapped across a relatively simply executed painting of a Roman Egyptian funerary portrait [47]. However, many ancient paintings, like the one in this present study, are more elaborate and complex, featuring two luminescent pigments and more extensive layering and mixing of the overall pigment palette. Much can be accomplished with single band luminescence imaging when luminescent pigments such as madder lake and Egyptian blue are separated and not mixed or layered [48]. However, if they are, by collecting spectral information, it should be possible to separate these species and understand how the artist used them. This is one of the advantages of LIS.

One of the challenges in applying RIS is the separation and mapping of pigments when mixed, especially in the presence of white pigments, as this diminishes the intensity of their spectral features. This problem is well known to spectroscopists and it is common to use first and second derivatives with respect to wavelength to enhance the spectral features. Here, this advantage is exploited by analyzing the first derivative of the reflectance image cube as well as the second derivative of the luminescence image cube. This approach has already been found useful in several cultural heritage science studies [45, 49].

This paper presents the results of applying RIS and LIS to a Roman Egyptian funerary portrait of a woman that contains many of the pigments discussed earlier that were available to ancient artists in this time period, including Egyptian blue and madder lake. This panel painting, from the Walters Art Museum collection (accession number 32.4, Fig. 1a), exemplifies the complexity of ancient painting. It features a masterful execution of the woman's flesh and form through extensive mixing and layering of pigments, and the surface is highly textured due to the binding medium. One of the most pressing questions was the identification, use, and possible mixing of Egyptian blue and madder lake in the portrait, and in particular the woman's pink-purple garment. The potential mixture of Egyptian blue and madder lake made LIS a very promising tool to identify, separate, and map both pigments reliably. Additionally, derivative analyses were applied in this
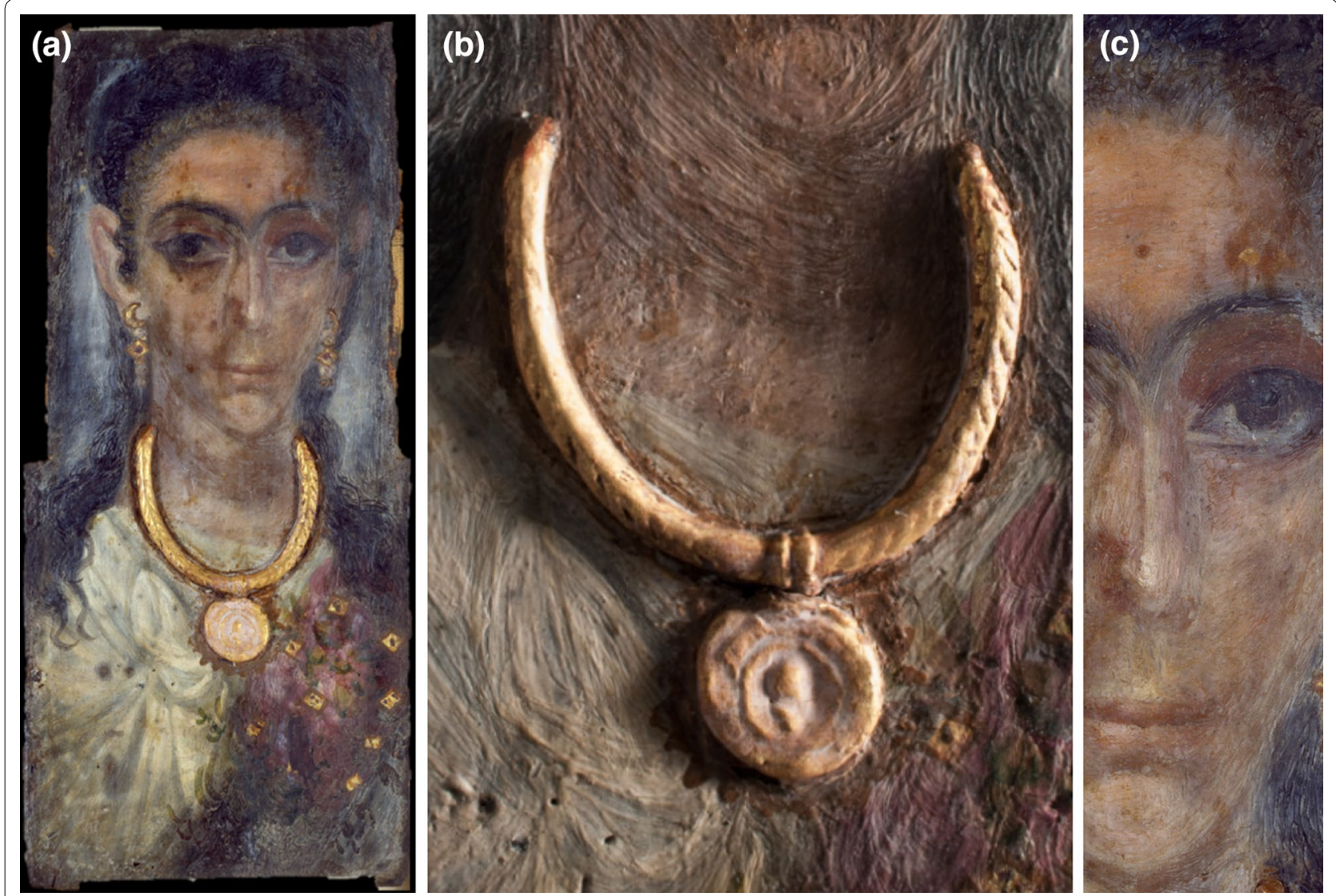

Fig. 1 a Roman Egyptian funerary portrait from the Walters Art Museum collection (accession number 32.4). b Close-up of the high-relief gilded necklace. c A detailed look at the naturalistic, multi-toned execution of the woman's face using shading and flesh-colored pigments 
study to create more accurate classification maps of the woman's naturalistic flesh tones and body to understand the artist's technological choices.

\section{Materials and methods}

\section{Roman Egyptian funerary portrait, A.N. 32.4}

The Walters Art Museum's Panel Portrait of a Woman (portrait 32.4) is characteristic of the extensive collection of Roman Egyptian funerary portraits excavated from burial sites in ancient Egypt. Often referred to as "Fayum" portraits, they feature a fusion of Hellenistic painting traditions with Egyptian funerary beliefs and serve as ethnographic records of social class and culture of Egypt in the Roman period by depicting naturalistic representations of ancient Egyptians on thin wooden panels or linen shrouds set over the faces of the deceased [50, 51]. Portrait 32.4, dating to 130-200 CE, represents a woman of high wealth and social status. Her white garments feature a knot that suggests she is a follower of the goddess Isis [52]. Draped across her proper left side is a pink-purple garment and what appear to be green leaves, though this region of the portrait has suffered some degradation and not all details are fully discernible. Pieces of gold foil on raised plaster decorate the pink-purple garment across her chest. Her accessories include a white veil that wraps around her body and gold jewelry. This portrait is rather unique for the high-relief gilded applications used for her crescent-shaped gold and imitated-pearl earrings and necklace (Fig. 1b). Her jewelry and the sun-shaped pattern of the bole (a reddish-brown clay used as a preparatory layer for gilding), the shape of the panel and the stylistic depiction connects this painting to portraits produced from the region of Antinoopolis, the city founded by the Roman emperor Hadrian in the second century CE [50].

Painted on beech wood [53] using both a brush for broader paint strokes and a hard tool for the highly textured hair and face, the intricate details in this portrait of the hair, the variations in flesh tones (Fig. 1c), the decoration of her veil and the shading used to produce a three dimensional effect for her knotted garment are a tribute to the craftsmanship of the ancient artist. The diversity of hues, and in particular the pink-purple garment that suggests the use of a red organic colorant, offers the portrait as a promising case study to apply advanced imaging spectroscopy techniques and data analysis for investigation.

\section{Instrumentation and data collection Imaging spectroscopy}

The 3D image cubes for both RIS and LIS were collected by a modified hyperspectral camera (SOC-730 Surface Optics Corporation) which is sensitive from 400 to $1000 \mathrm{~nm}$ [visible-to-near-infrared (VNIR)] with 2.4 $\mathrm{nm}$ spectral sampling. The camera produces $3 \mathrm{D}$ image cubes having 2D spatial sampling of 1024 by 1024 pixels and 256 spectral channels. The camera features a V10E transmission grating spectrometer (Specim Corporation) and a high sensitivity backside electron-multiplying (EM) CCD detector array (ProEM-1024, Princeton Instruments), designed for lower light levels imaging.

Reflectance (RIS) For RIS image data cube captures, the painting was illuminated using four Solux lamps (4700 K, $50 \mathrm{~W}$, Tailored Lighting, Inc.) mounted onto two light stands, projected approximately 45 degrees to the surface normal of the painting resulting in a light level of $\sim 1500$ lux at the painting. Two image scans $(1024 \times 1024$ pixels $)$ were collected $(250 \mathrm{~ms}$ integration time per image line) with a small amount of spatial overlap to allow for the image cubes to be mosaicked in post-processing.

Luminescence (LIS) To create the LIS image cube, a spectrally-filtered slide projector was used as an excitation source which passed light from $\sim 440$ to $525 \mathrm{~nm}$ (Semrock). A 533 to $1000 \mathrm{~nm}$ long pass filter (Semrock) was placed in front of the VNIR hyperspectral camera to block the reflected excitation light and allow for the collection of the emission from the painting. The LIS image collection was performed in a nearly dark room to reduce stray room light from interfering with the emission signals. The amount and spectral shape of the stray or background light was measured by looking at the signal off of a white standard which was included with the painting in the image scene. Two image LIS image cubes were collected with an integration time of $500 \mathrm{~ms}$ per image line with an EM setting focal plane set to 300. An image cube of the excitation light source off of a white panel in place of the painting was collected for use in the correction of excitation non-uniformity and pigment self-absorption.

\section{Fiber-optic reflectance spectroscopy}

A spectral radiometer (ASD FieldSpec 3, Malvern Panalytical) sensitive from 350 to $2500 \mathrm{~nm}$ [1.4 nm spectral sampling UV-VNIR and $2 \mathrm{~nm}$ sampling in the shortwave infrared (SWIR)] was used to provide additional spot reflectance spectra extending into the SWIR, 1000 to $2500 \mathrm{~nm}$, to supplement the VNIR hyperspectral reflectance data for characterizing the colorants and paint binding media. Data were collected using a $\sim 3 \mathrm{~mm}$ spatial diameter spot size with a $34 \mathrm{~ms}$ integration time per spectrum. Sixteen spectra were averaged for each measurement. 


\section{$X$-ray fluorescence (XRF) spectroscopy}

$\mathrm{X}$-ray fluorescence (XRF) spectroscopy was applied for elemental analysis on the portrait with a Bruker ARTAX XRF spectrometer equipped with an Xflash detector; data processing was completed using software version 7.1. Spot collection was acquired with a rhodium source at $50 \mathrm{kV}, 700 \mu \mathrm{A}$, and $200 \mathrm{~s}$ with a $1.5 \mathrm{~mm}$ diameter collimator and helium purge.

\section{Fourier-transform infrared (FTIR) spectroscopy}

Select microsamples were analyzed in transmission following compression in a diamond cell, using the Bruker Optics Tensor 27 spectrometer equipped with the Hyperion microscope. Collection comprised of 256 scans with $4 \mathrm{~cm}^{-1}$ resolution; no correction of the data was applied.

\section{Data analysis}

The 3D image cubes (both RIS and LIS) were analyzed using the ENVI image processing software package (Environment for Visualizing Images, L3Harris Technologies). This software was used to process, visualize, and perform statistical analysis on 3D image datasets. In general, multivariate statistical analysis algorithms in ENVI were used to find the spectral endmembers from the reflectance and luminescence image cubes. Then, maps of the endmembers were made by using the Spectral Angle Mapper (SAM) algorithm to generate the classification maps. The spectral features of the endmember spectra were used to identify the artist materials present.

Both RIS and LIS image cubes were first pre-processed by subtracting the dark image cube to remove the dark offset. For RIS, an image cube of a diffuse white panel (98\% reflective Labsphere white standard) was collected and the associated dark cube subtracted. Next the two dark-corrected RIS image cubes of the painting were divided by the dark-corrected cube of the white standard in order to convert the RIS image cubes to apparent reflectance image cubes. Finally, the two apparent reflectance image cubes were mosaicked together to produce the final apparent reflectance image cube using in-house registration software developed by Conover et al. [54] with a final spatial resolution of $0.7 \mathrm{~mm} /$ pixel.

For LIS, the dark-subtracted LIS cubes were next corrected for non-uniform illumination and variations in the throughput of the hyperspectral camera using the image cube acquired of the excitation source off the white panel. Next, a previously developed algorithm for correcting the emission image cube for absorption effects when the painting is excited over a small spectral range was used [45]. This algorithm was developed around a fluorescence correction method by Lagorio et al. [55] to calculate the true emission spectrum from a spectrum collected at single site and excited by a single excitation wavelength. This method has been shown to work well to correct emission spectra for luminescent paints when excited by a laser [46]. The algorithm used here requires as input the corrected luminescence image cube (after subtracting the dark cube and correction for non-uniform excitation and camera throughput variations over the field of view), the spectral profile of the excitation source and the apparent reflectance image cube that covers the excitation spectral range.

To improve extraction of pigment signatures from intimate mixtures, mixed signals from layering, and trace materials, derivative calculations were applied to the image cubes. This approach is already effective in remote sensing studies as a means to accurately discriminate minerals and estimate relative amounts by looking at the first and second derivatives values of reflectance profiles [56]. Most pigments have characteristic VNIR reflectance spectra with diagnostic absorption, peak maxima, and inflection point values in their spectral profiles $[57,58]$. The first derivative calculation effectively identifies these values through zero crossings (maxima/minima in the original reflectance cube) and peak values (the inflection point in the original reflectance cube), and suppresses the background from a white colorant, thus improving extraction in the statistical analyses. Derivative calculations of the LIS image cube also enhances signals from painted regions containing lesser amounts of luminescent pigments which have emission peaks in the VNIR.

Several different methods were utilized to extract spectral endmembers from the image cubes. The first was ENVI's Spectral Hourglass Wizard (SHW), an operational process that begins with spectral data-dimensionality reduction by a minimum noise fraction (MNF) transform (essentially two principle component analysis transforms that decorrelate and noise-whiten the data) to manage the high volume of the image cubes. Then a pixel purity calculation using a convex geometry framework identifies the most extreme pixels, which are manually clustered using the n-D space visualizer tool [59]. The second approach utilized ENVI's Sequential Maximum Angle Convex Cone (SMACC) algorithm, a convex factorization approach that treats pixels as extreme vectors that form convex cones. SMACC iteratively searches for spectral profiles that produce the largest angles within the cones, which become the resultant endmembers [60]. Finally, endmembers were also selected manually from averaged spectral profiles from regions of interest (ROI) identified in the painting.

The chosen endmembers were then input into ENVI's Spectral Angle Mapper (SAM) as a reference set. This is an automated tool that identifies which spatial pixels in the image cube have reflectance spectra that match closely to those in the endmember set. SAM determines 
the spectral similarity by treating the spectra in the spatial pixels and those in the reference set as vectors to calculate the spectral angle between them. The smaller the spectral angle, the higher the degree of spectral similarity. SAM outputs maps for each reference endmember that shows the spatial pixels in the image cube with the highest similarity, which appear brightest in the maps. A false color image featuring the entire reference endmember set is also produced that shows how each endmember is mapped over the portrait's surface with respect to one another. This comprehensive mapping relies on specified spectral angles for each endmember, as determined from the individual maps.

An alternative mapping approach to SAM was also applied to the LIS image cube to produce material maps, called linear spectral unmixing [61]. A linear unmixing model was used to fit the luminescence spectra as a linear sum of three endmembers to calculate the contributions of individual endmembers to the total signal measured and produce their respective abundance maps. The abundance map of each endmember is a plot of the amplitude of each endmember after the fitting per spatial pixel throughout the image scene. This research explored how different luminescence signals, arising from both pigment and non-pigment sources, contributed to the total emission signal recorded in the LIS dataset. These abundance maps were processed by applying a $3 \times 3 \mathrm{ker}-$ nel median filter, effective for removing noise at the single pixel level.

\section{Results \\ Reflectance \\ Pigment identification and tonal variations}

From the analysis of the first derivative RIS cube, ten distinct spectral endmembers were identified in the portrait (Fig. 2). The woman's flesh tones, clearly the most complex portion of the painting with respect to materials mixing and layering, are represented by five different endmembers, constituting five unique mixtures predominantly comprised of ochre pigments of varying amounts mixed with a white pigment to adjust their hues. Her white garments are also represented by three endmembers, as the artist used shading and bright tones to create a 3D effect. RIS analyses suggested relatively straightforward applications in the pink-purple garment, her jewelry, the leaves, and the highlight of the ringlets in her hair, a material which we will see was also used in the flesh tones. The first derivative RIS endmembers (Fig. 2d), their hues, and the constituent painting materials they are composed of, identified through complementary
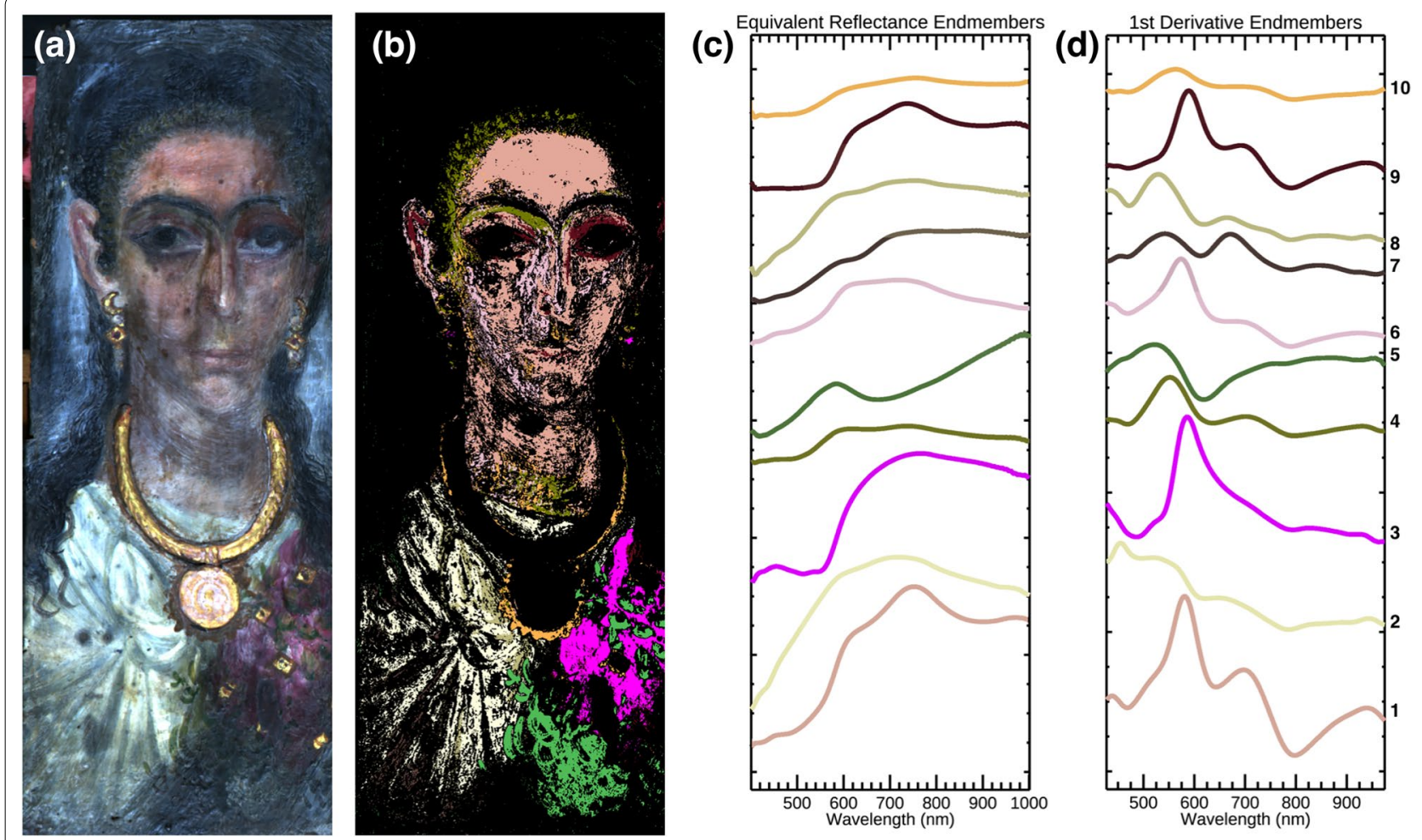

Fig. 2 a Three-band image of portrait A.N. 32.4 extracted from the reflectance cube. b Spectral angle map of first derivative endmembers extracted (d). The equivalent reflectance spectra are in c 
reflectance, luminescence, XRF, and FTIR analyses, are listed in Table 1 . Their chemical mapping is visualized in Fig. 2b.

The spectral endmembers (Fig. 2c, d) represent various intimate mixtures containing a hematite-rich red ochre, a goethite-rich yellow ochre, natrojarosite $\left((\mathrm{Na}) \mathrm{Fe}_{3}^{3+}(\mathrm{OH})_{6}\left(\mathrm{SO}_{4}\right)_{2}\right)$, madder lake, copper $(\mathrm{Cu}(\mathrm{II}))$ carboxylate, and lead white (cerussite/hydrocerussite). Hematite features a characteristic inflection point at 585 $\mathrm{nm}$ and absorption at $660 \mathrm{~nm}\left({ }^{6} \mathrm{~A}_{1 \mathrm{~g}}\left({ }^{6} \mathrm{~S}\right) \rightarrow{ }^{4} \mathrm{~T}_{2 \mathrm{~g}}\left({ }^{4} \mathrm{G}\right)\right)$, a peak maximum at $750 \mathrm{~nm}$ and broad NIR absorption at $\sim 870 \mathrm{~nm}\left({ }^{6} \mathrm{~A}_{1 \mathrm{~g}}\left({ }^{6} \mathrm{~S}\right) \rightarrow{ }^{4} \mathrm{~T}_{1 \mathrm{~g}}\left({ }^{4} \mathrm{G}\right)\right)$. Goethite is identified by a shoulder at $445 \mathrm{~nm}\left({ }^{6} \mathrm{~A}_{1 g}\left({ }^{6} \mathrm{~S}\right) \rightarrow{ }^{4} \mathrm{~A}_{1 \mathrm{~g}},{ }^{4} \mathrm{E}_{\mathrm{g}}\left({ }^{4} \mathrm{G}\right)\right)$, an inflection at $550 \mathrm{~nm}$ and absorption at $670 \mathrm{~nm}$, as well as a peak maximum at $765 \mathrm{~nm}$ and a broad NIR absorption centered at $925 \mathrm{~nm}\left({ }^{6} \mathrm{~A}_{1 \mathrm{~g}}\left({ }^{6} \mathrm{~S}\right) \rightarrow{ }^{4} \mathrm{~T}_{1 \mathrm{~g}}\left({ }^{4} \mathrm{G}\right)\right)[62,63]$.

First derivative reflectance spectral analysis helped to determine endmembers representing different mixtures of primarily red and yellow ochre pigments used for multiple flesh tone hues in the woman's face and neck. The large peaks' maxima from $\sim 550$ to $590 \mathrm{~nm}$ correspond to the inflection points of the ferric oxide/oxyhydroxide minerals in the pigments, which can be distinguished by comparison to reference reflectance spectra. The secondary peaks from $\sim 615$ to $750 \mathrm{~nm}$ provide absorption information corresponding to those at $660-670 \mathrm{~nm}$ in the reflectance spectra. Smaller secondary peaks can indicate high amounts of pigment, causing an absorption saturation, or mixtures with a black pigment.

The artist applied extensive shading on the woman's facial features using a range of darker tones, such as her eyelids, the sides of her nose, her ears, and neck, as well as her forehead, tip of her nose, and chin. The hues in her face comprise deep red-brown, light pink, yellow, and white tones. First derivative endmembers 1, 4, 6, 9 and 10 show varying amounts of a red ochre, a yellow ochre,

Table 1 First derivative endmember results from the RIS studies, for which materials assignment is attributed by complementary imaging, FORS, XRF, and FTIR analyses

\begin{tabular}{|c|c|c|c|c|c|c|}
\hline Region & Hue & Endmember & $\begin{array}{l}\text { RIS spectral } \\
\text { features }(\mathrm{nm})\end{array}$ & $\begin{array}{l}\text { FORS spectral } \\
\text { features }(\mathrm{nm})\end{array}$ & XRF elements & Material(s) assignment \\
\hline $\begin{array}{l}\text { Flesh (forehead, facial } \\
\text { shading) }\end{array}$ & Light pink & 1 & $\begin{array}{l}456(\mathrm{~s}), 582(\mathrm{i}), 670,752 \\
(\mathrm{~m}), 901\end{array}$ & $\begin{array}{l}452(\mathrm{~s}), 582(\mathrm{i}), 670,750 \\
(\mathrm{~m}), 888,1215,1394 \\
1419,1730,1763,1825 \\
1940,2275,2311,2352\end{array}$ & $\mathbf{P b}, \mathrm{Fe}$ & $\begin{array}{l}\text { Red ochre, yellow ochre, } \\
\text { lead white }\end{array}$ \\
\hline Garment (bright areas) & White & 2 & $\begin{array}{l}435,590(\mathrm{~s}), 720(\mathrm{~m}) \\
940\end{array}$ & $\begin{array}{l}434,590(\mathrm{~s}), 743(\mathrm{~m}) \\
930,1215,1394,1419 \\
1542,1730,1763,1825 \\
1940,2012,2055,2275 \\
2311,2352\end{array}$ & $\mathrm{~Pb}, \mathrm{Cu}, \mathrm{Fe}$ & $\begin{array}{l}\text { Natrojarosite, lead white, } \\
\text { Egyptian blue }\end{array}$ \\
\hline Earrings, garment & Pink/purple & 3 & 514,547 & $\begin{array}{l}515,547,1215,1394 \\
1419,1730,1763,1825 \\
1940,2012,2056,2275 \\
2311,2352\end{array}$ & $\mathrm{~Pb}, \mathrm{Ca}, \mathrm{Cu}, \mathrm{Fe}, \mathrm{Al}$ & $\begin{array}{l}\text { Madder lake, natroja- } \\
\text { rosite, and lead white } \\
\text { (underlayer) }\end{array}$ \\
\hline Hair braid; eye line & Olive green & 4 & $\begin{array}{l}435,454(\mathrm{~s}), 552(\mathrm{i}), 660 \\
740(\mathrm{~m}), 920\end{array}$ & - & $\mathrm{Fe}, \mathrm{Pb}, \mathrm{Ca}$ & $\begin{array}{l}\text { Yellow ochre, lead white, } \\
\text { natrojarosite }\end{array}$ \\
\hline Leaves & Green & 5 & $522(\mathrm{i}), 585(\mathrm{~m}), 674$ & $\begin{array}{l}523(\mathrm{i}), 581(\mathrm{~m}), 661 \\
1215,1394,1419,1543 \\
1730,1763,1825,1940 \\
2012,2055,2275,2311 \\
2352\end{array}$ & $\mathrm{Cu}, \mathrm{Pb}, \mathrm{Fe}$ & $\begin{array}{l}\text { Copper carboxylate, lead } \\
\text { white (underlayer) }\end{array}$ \\
\hline $\begin{array}{l}\text { Flesh (skin tones, } \\
\text { highlights) }\end{array}$ & White-pink & 6 & $\begin{array}{l}456(s), 575(i), 670,736 \\
(m), 860\end{array}$ & - & - & $\begin{array}{l}\text { Yellow ochre, red ochre, } \\
\text { lead white }\end{array}$ \\
\hline Garment lines & Grey/black & 7 & $\begin{array}{l}437,455(s), 542(i), 625 \\
671(i), 825\end{array}$ & - & - & $\begin{array}{l}\text { Natrojarosite, Egyptian } \\
\text { blue, lead white }\end{array}$ \\
\hline Garment lines & Yellow & 8 & $\begin{array}{l}435,456(\mathrm{~s}), 530(\mathrm{i}), 640 \\
750(\mathrm{~m}), 820\end{array}$ & - & - & Natrojarosite, lead white \\
\hline Ear line; eye line & Deep red & 9 & $590(\mathrm{i}), 675,739(\mathrm{~m}), 901$ & $\begin{array}{l}586(\mathrm{i}), 660,745(\mathrm{~m}) \\
874,1215,1394,1419 \\
1730,1763,1825,1940 \\
2275,2311,2352\end{array}$ & - & Red ochre \\
\hline Bole & Orange-red & 10 & $\begin{array}{l}434,562(i), 670,755 \\
(m), 932\end{array}$ & $\begin{array}{l}562(\mathrm{i}), 675,768(\mathrm{~m}), 881 \\
1215,1394,1419,1730 \\
1763,1825,1940,2275 \\
2311,2352\end{array}$ & $\mathrm{Fe}, \mathrm{Pb}, \mathrm{Cu}$ & Red ochre, yellow ochre \\
\hline
\end{tabular}


natrojarosite and lead white to decorate and accentuate certain areas of her face. Endmember 1, found in forehead and facial shading, has spectral features at $456 \mathrm{~nm}$ (shoulder), $582 \mathrm{~nm}$ (inflection), $670 \mathrm{~nm}$ (absorption), $752 \mathrm{~nm}$ (peak maximum), and $901 \mathrm{~nm}$ (NIR absorption), which clearly shows a mixture of hematite-rich red and goethite-rich yellow ochres. The white pigment was identified by XRF as lead white due to the presence of $\mathrm{Pb} \mathrm{L}_{\alpha}$ and $\mathrm{L}_{\beta}$ characteristic X-ray energies measured at 10.55 and $12.61 \mathrm{keV}$, respectively, and the $\mathrm{M}_{\alpha}$ emission at $2.34 \mathrm{keV}$. This lead white pigment is believed to be a mixture of cerussite $\left(\mathrm{PbCO}_{3}\right)$ and hydrocerussite $\left(\mathrm{Pb}_{3}\left(\mathrm{CO}_{3}\right)_{2}(\mathrm{OH})_{2}\right)$, produced by placing lead sheets above acidic baths that are sealed for extended periods of time to induce corrosion that produces both lead white phases $[27,64]$. Though the characteristic $\mathrm{OH}$ stretching feature of hydrocerussite was absent at $1449 \mathrm{~nm}$ in the FORS spectra $[65,66]$, it is quite rare for natural cerussite to be used. Natrojarosite, a Na-rich jarosite, was identified by a small characteristic absorption due to the electronic transition at $\sim 433-435 \mathrm{~nm}\left({ }^{6} \mathrm{~A}_{1 \mathrm{~g}}\left({ }^{6} \mathrm{~S}\right) \rightarrow{ }^{4} \mathrm{~A}_{1 \mathrm{~g}}\right)$. FORS and XRF confirmed the presence of a Na-rich jarosite mineral due to the lack of $\mathrm{K}$ in the XRF spectra and the presence of the $1543 \mathrm{~nm}$ first $\mathrm{O}-\mathrm{H}$ stretching overtone in the infrared portion of the FORS spectra [67]. The difference in radii of $\mathrm{Na}$ vs $\mathrm{K}$ as well as their charge/radius values also manifest in diagnostic shifts in the absorption spectra, such as the feature located at 433 $\mathrm{nm}$, which is indicative of natrojarosite $[68,69]$. Natrojarosite has been previously identified in other mummy portraits as well as in Hellenistic and Roman mural paintings and funerary stelae $[10,47]$.

Endmember 6 contains red and yellow ochres, mixed with lead white (inferred from $\mathrm{Pb}$ peaks in XRF data), to produce a white-pink flesh tone but presents a unique mixture based on the spectral features' positions at different wavelengths compared to endmember 1 . Endmember 4 , which maps to the olive green-toned ringlets in the hair braid across her forehead and the proper right eyeline under her eyebrow, is a mixture of yellow ochre, lead white, natrojarosite (identified by a $435 \mathrm{~nm}$ narrow absorption), and possibly a black pigment to darken the hue. The final flesh tone, mapped by endmember 9 on her ear and proper left eyeline, is a deep red hue produced by a rich application of red ochre.

Natrojarosite was also found throughout the white garments, in different tones mapped by endmembers 2, 7 and 8, mixed with lead white and Egyptian blue (the latter identified by luminescence mapping, to be discussed in the next section). Regions appearing brighter such as noticeable brush strokes and dots show stronger signatures of natrojarosite (endmember 2). Weaker signals were found in the veil and the earring of the woman.
The white garments also feature dark and yellow-toned stripes, most likely to create shadows and highlights imitating the appearance of the knot and folds in the cloth. The yellow stripes were mapped by endmember 8 , while the darker stripes were mapped by endmember 7 , which has an $\sim 630 \mathrm{~nm}$ absorption in the reflectance spectrum. Because the white hues were produced by a mixture with natrojarosite (which has an absorption at $\sim 640-650 \mathrm{~nm}$ ), lead white, and Egyptian blue, the complexity of the intimate mixture does not permit the latter's identification based only on a reflectance signature.

The orange-red bole, which was used as a preparatory layer and outline decoration for the gold jewelry, was mapped by endmember 10 (also found in small amounts in the flesh tone) which contains a mixture of red and yellow ochres, as well as a subtle presence of natrojarosite. Endmember 5, which maps to the green leaves over the pink and white garments, features a spectral profile similar to that of copper carboxylate, most likely produced by mixing copper acetate (i.e. verdigris) with heated beeswax. FTIR analysis on a sample acquired from green applied over the white garment identified verdigris by characteristic bands at 2924, 2853, 1591, 1555, and 1417 $\mathrm{cm}^{-1}$. Thus, verdigris appears to be the source material for the copper carboxylate pigment.

Endmember 3, which identified madder lake by its double absorption at 514 and $547 \mathrm{~nm}$, was mapped to the pink-purple garment; however, it will be shown that this did not map all applications of the pigment in the portrait, due to low amounts, as well as being mixed and layered with other pigments, thus masking/modifying its characteristic reflectance signature.

Two black colorants were distinguished in this painting. The wooden panel was first primed with a black wash containing $\mathrm{P}$ and $\mathrm{Ca}$ that suggests the use of bone black. The dark tones in the painting, such as the background and the woman's hair, contain high levels of $\mathrm{Pb}$, possibly due to a mixture of lead white as there are white/ grey tones both in the hair and background, and Fe. The reflectance values in the VNIR stay primarily under $5-7 \%$ of the total signal, suggesting that a carbon-based black is the primary component of the black paint. The black pigment was also used for the eyes and eyebrows, layered over the deep red pigment to soften the black tone and produce a range of brown to red hues.

Finally, wax was confirmed in the portrait as a binding media in the FORS spectra acquired from various hues, identified by the position of $\mathrm{CH}_{2}$ asymmetric/symmetric plus bending fundamental modes at 2311 and $2352 \mathrm{~nm}$, as well as the first overtones of $\mathrm{CH}_{2}$ asymmetric/symmetric stretching at 1730 and $1763 \mathrm{~nm}$ [70-73] (Fig. 3). FTIR further confirmed the presence of beeswax with characteristic bands at 2954, 2847, 1735, 1712, 1472, 1463, 1175, 


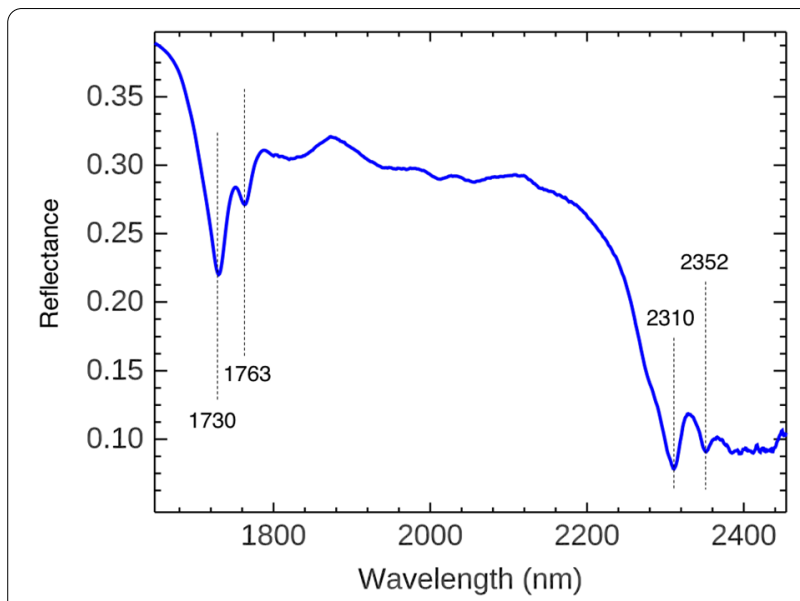

Fig. 3 Characteristic absorptions in the short-wave infrared at 1730, 1763,2310 , and 2352 due to $\mathrm{CH}_{2}$ bending and stretching modes identify beeswax as the binding medium

730 and $720 \mathrm{~cm}^{-1}$. The visual characteristics of the binding media also suggest the use of beeswax, and this result is consistent with technical analyses of other mummy portraits that have been well characterized to have been painted with beeswax $[47,74]$.

\section{Gold and white applications}

The gold jewelry and the lead white applications in the veil and eye were challenging to extract representative endmembers to map using the first derivative, which is sensitive to subtle differential changes in the reflectance profile. The specular reflection, or glints, off the gold leaf, which was applied in high relief does not have any spectral information. The gold jewelry was more robustly mapped by a diffuse reflectance endmember showing a broad reflectance (Fig. 4a, b) and characterized by XRF as an alloy of gold and silver, most likely electrum. While VNIR spectral mapping was not effective for lead white, due to the very thin application of the veil and mixtures with other pigments, a first derivative eigenimage produced from the MNF transform emphasized the applications of white in the portrait (Fig. 4c), highlighting features such as the proper left eye and emphasized the veil wrapping around the body of the woman at the bottom of the portrait, giving an enhanced sense of dimensionality to the painting. Additional details such as the fabric mesh of the veil are clearly visible, and it appears that the veil itself has small adornment features, appearing both on the top of her head and along the draped edge on her proper left side.

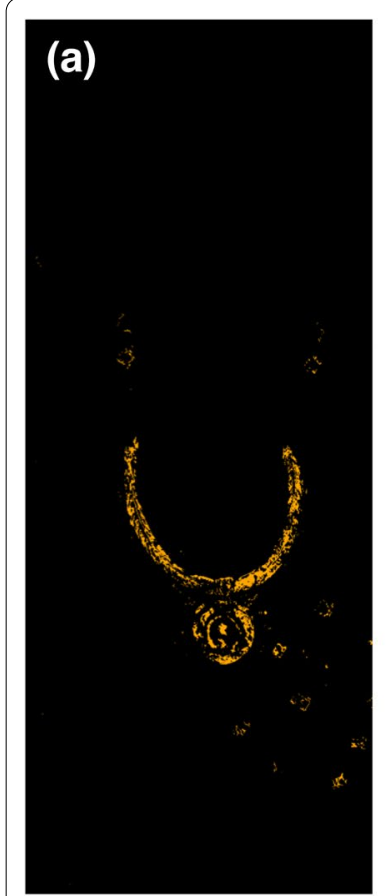

(b)

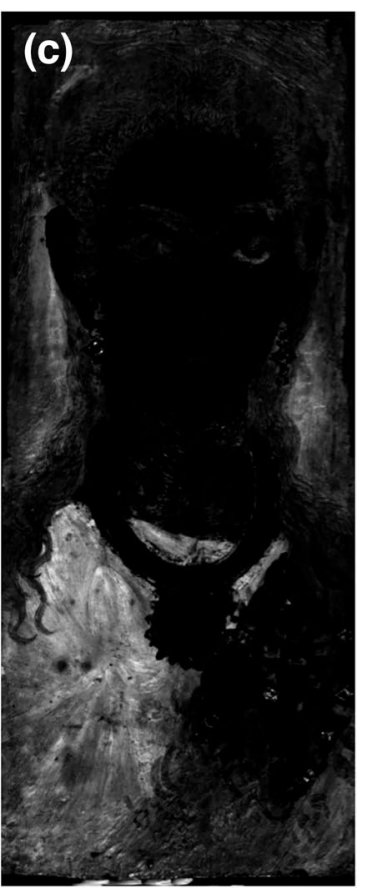

Fig. 4 a Mapping of gold applications in the portrait using the endmember in $\mathbf{b} ; \mathbf{c}$ MNF eigenimage that emphasizes white applications in the portrait 


\section{Luminescence}

First derivative analysis of the reflectance data cube provided identification and a preliminary mapping of madder lake. The robustness of this mapping is limited, though, in regions where its reflectance signature was masked or convoluted by other spectral signatures. The emission profiles, however, once corrected for self-absorption and absorption by other pigments, should remain relatively unchanged by the rest of the pigment palette identified in Table 1, as those materials do not have visible-induced visible photoluminescence. RIS analyses were also unable to reliably identify Egyptian blue.

Endmember extraction from the corrected LIS data cube yielded two distinct endmembers: one featuring a peak emission at $605 \mathrm{~nm}$ (EM 1), corresponding to madder lake, and the other in the NIR at $888 \mathrm{~nm}$ (EM 2), attributed to Egyptian blue (Fig. 5a). In the portrait there is a pseudo-emission signal in the visible wavelength range not associated with any luminescent pigment that is roughly proportional to the reflectance of the portrait, possibly due to the presence of stray light. Though it does not interfere with Egyptian blue's emission signal, it does slightly compromise the fluorescence profile of madder lake. We applied linear spectral unmixing to understand how Egyptian blue, madder lake, and the background emission contribute to the total luminescence signal in the image cube. To do so, the Egyptian blue endmember was first corrected by removing the fluorescence peak in the visible wavelength range, which was ascribed to stray light. The two pigment endmembers and a manually-selected reference background emission spectrum (Fig. 5a) were then linearly unmixed to map the distribution of the background emission, madder lake, and Egyptian blue (Fig. 5b-d).

The LIS abundance map for madder lake (Fig. 5c) shows a broader pigment application compared to the map obtained from the RIS endmember for madder lake. The pink garment, made up of different hues of light and dark pink and purple with varying amounts of white and featuring regions of deterioration, is now more comprehensively mapped. Furthermore, the earrings are better characterized compared to the RIS first derivative mapping for madder lake. A subtle feature of madder paint also appears in the proper right eye of the woman.

The application of Egyptian blue was initially inferred by a visible-induced NIR photograph produced by the Walters Art Museum (Fig. 6a). The photograph shows a strong luminescence arising from the white garments and the green leaves on the pink-purple garment near the woman's proper left shoulder. There is also a weaker but (a)

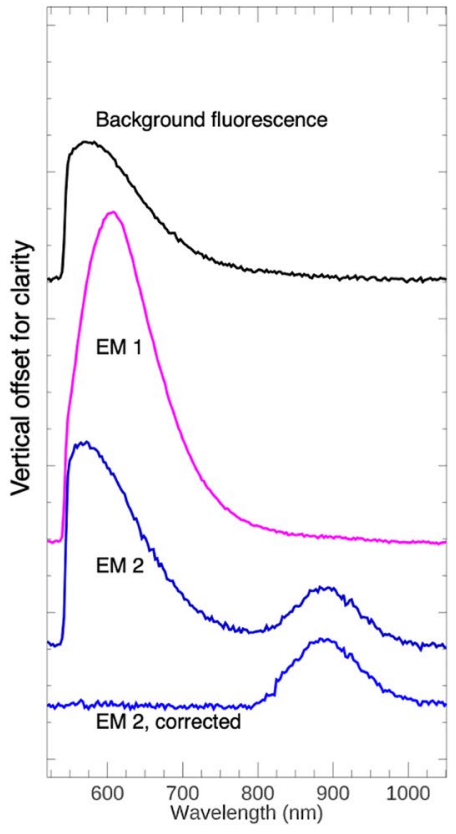

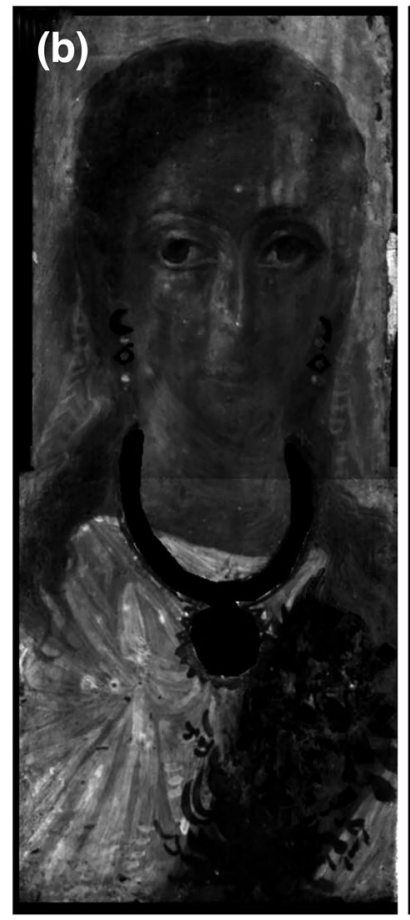
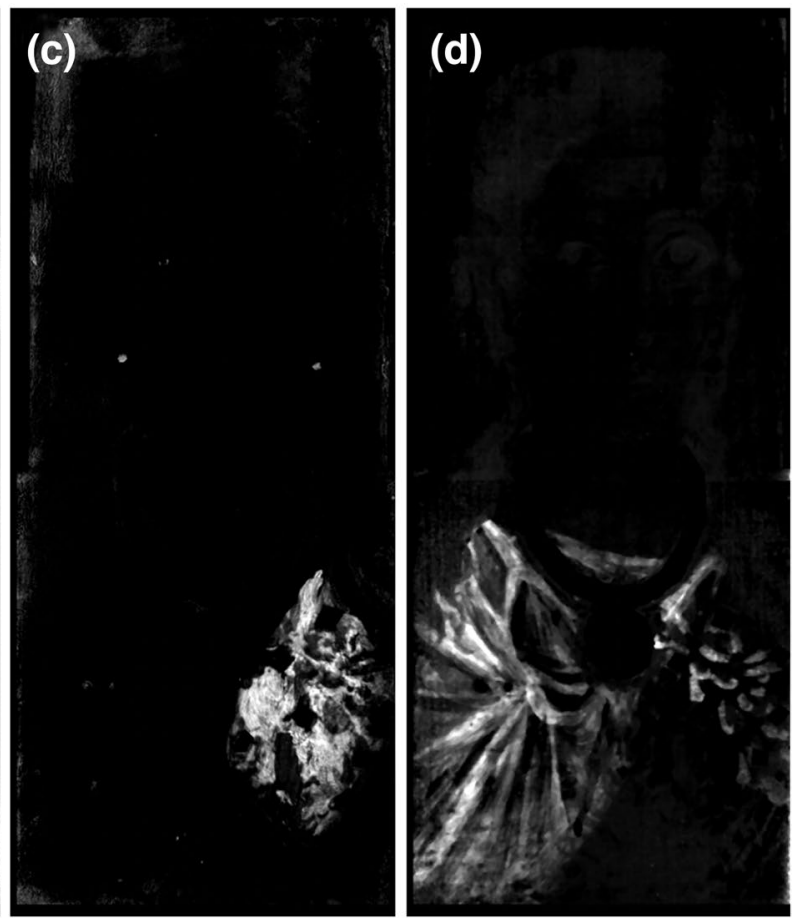

Fig. 5 a Endmembers used for linear unmixing. EM 2, corresponding to Egyptian blue, was corrected to remove the stray light background. b Emission mapped in the portrait using the background fluorescence endmember. c Madder lake abundance map produced from the linear unmixing of EM 1.d Egyptian blue abundance map produced from the linear unmixing of corrected EM 2 

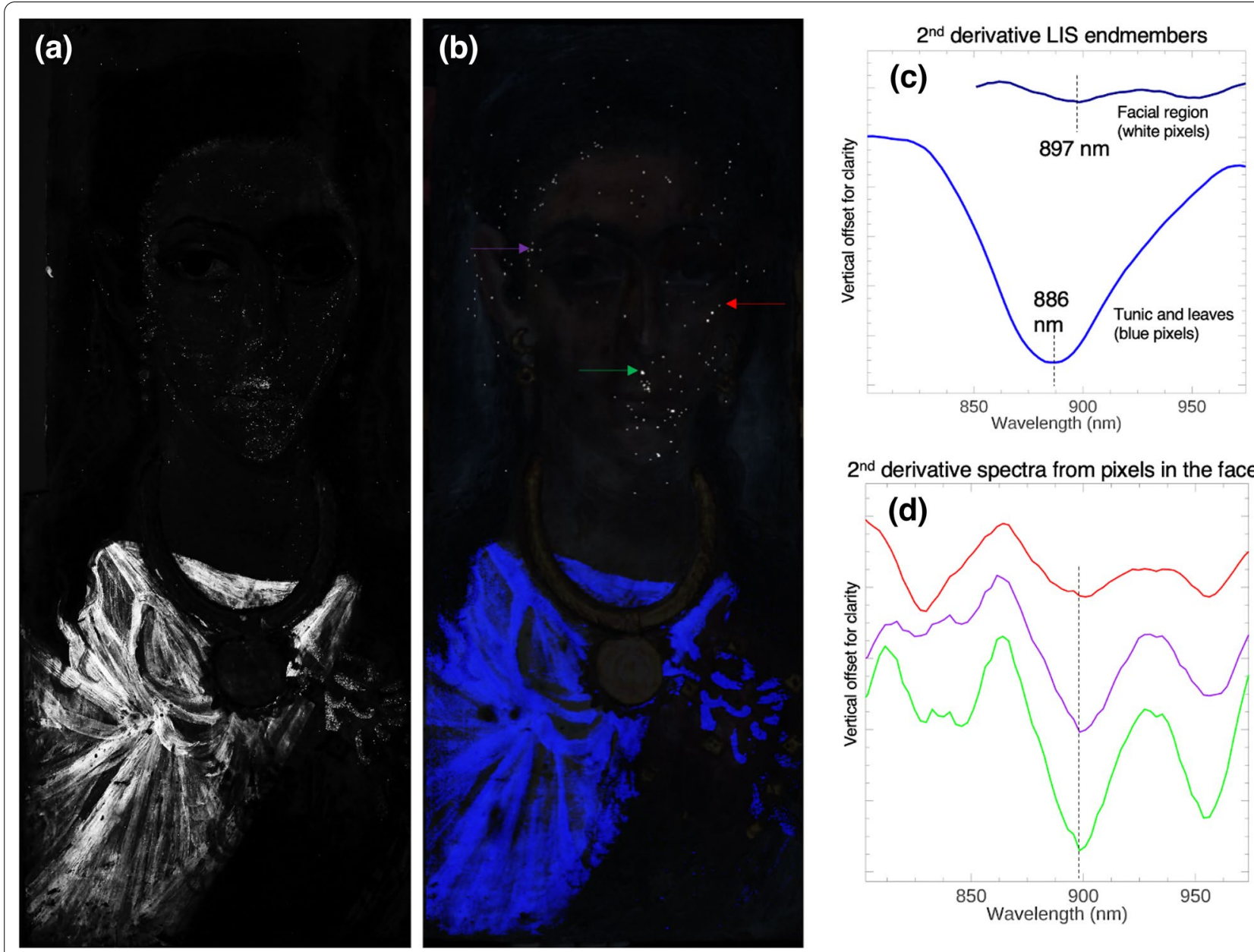

$2^{\text {nd }}$ derivative spectra from pixels in the face

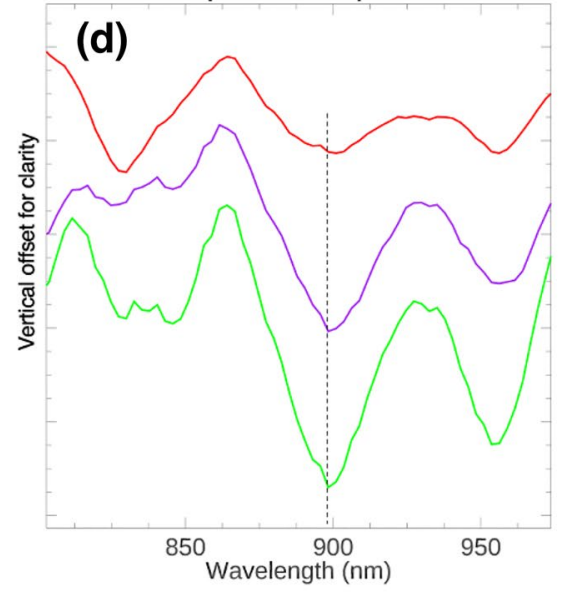

Fig. 6 a Visible-induced NIR luminescence photograph (Walters Art Museum). b Combined maps (abundance map for blue endmember, spectral angle map for black endmember) for the second derivative Egyptian blue endmembers in c, overlaid with $10 \%$ transparency onto the portrait to show luminescence distribution. $\mathbf{d}$ Spectra from mapped pixels in the woman's face in $\mathbf{b}$, designated by the horizontal arrows, confirm that the luminescence seen in the photograph in $\mathbf{a}$ is indeed Egyptian blue, due to the $897 \mathrm{~nm}$ spectral feature, and able to be mapped by LIS

still distinct luminescence in the outline of the figure's face, in the proper left cheek, and in the upper lip and chin. The linearly unmixed abundance map for Egyptian blue shows emission from the white garments and the green leaves (Fig. 5d). By relying on a spectral signature rather than total light capture (as done in multiband photography), a more reliable mapping and interpretation of the pigment's application by the ancient artist to paint the white clothing and the leaves is available; in fact, the green leaves appear to have a stronger mapping in the abundance map than what was identified in the NIR photograph. LIS also overcomes the challenge of attempting to map this pigment using RIS data, as the amounts were too low in the pigment mixtures to reliably assign its absorptions in the visible. However, luminescence mapping within the facial region was less successful, most likely due to the extremely low amount of Egyptian blue.
To further access weaker emission signals, a second derivative calculation was applied to the LIS cube, and the analyses were localized to the NIR in two spectral ranges: $800-975 \mathrm{~nm}$ and $850-1000 \mathrm{~nm}$, where the data contains little to none of the stray light. Two endmembers were selected: the first endmember was found using the SHW (800-975 nm), and the second endmember was found manually from an ROI in the woman's face (850$1000 \mathrm{~nm}$ ). The first endmember, mapped in blue pixels in Fig. $6 \mathrm{~b}$ using an abundance map to show the variation in amount, corresponds to the white garments and leaves. The local minimum for the NIR emission in the second derivative appears at $886 \mathrm{~nm}$, which closely matches the peak emission value of EM 2 applied in the linear unmixing, which accounts for this similar mapping behavior. However, the green leaves are mapped more comprehensively than what was seen in Fig. 5d. 
The second endmember, extracted from the facial region, features a weaker, shifted emission at $897 \mathrm{~nm}$ which was able to map, in white pixels, some Egyptian blue in the upper lip, the chin, the proper left cheek, and the outlining of the proper right side of her face. This mapping was performed as a spectral angle map to give all pixels equal intensity to show the distribution more clearly as the amount is quite low in the face. To confirm that the mapping's bright spots in the face (indicated by the red, green, and purple arrows) were Egyptian blue, their associated spectra were extracted and are shown in Fig. 6d. Comparison of these spectra to the second endmember show similar profiles with the second derivative feature of NIR emission at $897 \mathrm{~nm}$.

\section{Discussion}

The pigment distributions of the woman's flesh tones, provided by the labeled maps, confirm that the artist followed the practices of skiagraphia, the use of shading and contour, with different amounts and mixtures of ochre pigments, to create a naturalistic depiction of the face. This technique was discussed in ancient texts such as Pliny the Elder's, in which he attributed the practice of skiagraphia to the fifth century BCE artist Apollodorus, the "shadow painter". Theophrastus in his treatise, $O n$ Stones, also described the use of red and yellow ochres to execute flesh tones in figurative painting $[28,29]$. Thus, the use of earth pigments is not surprising; interestingly, these treatises do not discuss the use of Egyptian blue being added into the flesh tones, though we see this practice used here and in other Roman Egyptian funerary portraits $[75,76]$, as well as in ancient Cypriot painting [26].

Egyptian blue was identified and mapped conclusively by LIS rather than reflectance spectroscopy. While ideal excitation of Egyptian blue is usually done in the red where its absorption is strongest, this would preclude the ability to simultaneously map madder lake. In the portrait, the dominant use of Egyptian blue appears in the white garments to give a cold white tone. Ancient artists often applied Egyptian blue in layers and mixtures of pigments to produce certain visual aesthetics. Mixtures with white pigments offered a "cold" tone in the clothing and eyes of figurative paintings $[33,77]$ or produced a light blue backdrop [26]. As noted above, earth pigments dominated the execution of the flesh tones, but the use of Egyptian blue, though not documented in ancient records, was also evident. The use of Egyptian blue here, found around the outer edges of her face and within the flesh tones on her lip, nose, and chin, was most likely used to create shading in the face.

The distribution of natrojarosite in the white garments revealed by the RIS endmember maps highlights a new use of this pigment in ancient painting. Specifically, natrojarosite is seen in the brightest regions of the white tunic, likely chosen for this application as it is a brilliant yellow mineral. Thus, lead white, natrojarosite, and Egyptian blue were used together in varying amounts to create the "body" and dimensionality of the folds and knots of the woman's garments.

This portrait also features one of the few confident identifications of a green copper carboxylate pigment used in funerary portraits $[47,76]$, produced by mixing verdigris with heated beeswax [78]. While this pigment was solely used for the green leaves, LIS and RIS mapping reveals different artistic execution of the leaves throughout the painting. Over the pink-purple garment on her proper left shoulder, the leaves are painted with both the copper carboxylate pigment and Egyptian blue, as indicated by both mapping of endmember 5 in the RIS data set (Fig. 7b, d) and the intense luminescence emission (Fig. 7c, e). This bright emission is relatively absent in the green leaves at the bottom of the portrait and over the white garments. It is also noted the LIS maps showed much more specificity in the Egyptian blue-decorated green leaves than what was inferred by visible-induced NIR luminescence photography, which helped facilitate this distinction in their execution. The intentional accenting of the green leaves over the garment with Egyptian blue, not detectable by the naked eye, further emphasizes the depth of the artist's creative vision and skill.

The chemical maps of madder lake obtained from RIS and LIS gave different but overlapping distributions. Mapping the reflectance signature is impacted by variations in its quantity, presence of degradation, and mixtures with other pigments. However, the luminescence data can be corrected for self-absorption and absorption by other pigments which should produce a consistent emission profile to be mapped. Therefore, the map from LIS showed a much more extensive use of madder lake than by the reflectance map. A study of emission peak maxima from an ROI representing the eye, earrings, and garment revealed a distribution of peak values. A majority of peak wavelengths from the ROI were recorded between 595 and $601 \mathrm{~nm}$ but a non-trivial distribution extends to $610 \mathrm{~nm}$. These differences in the peak values after correction for self-absorption do not necessarily suggest a different red lake material but rather can be attributed to the fact that the madder lake pigment was applied in layers, and the emission of the lower layers was absorbed by the top-most layers, shifting the fluorescence emission to longer wavelengths. The correction applied to the LIS data cube only accounts for a single layer with homogeneous distribution of material, an assumption that does not accurately model a complex painting. Additionally, the presence of stray light can 

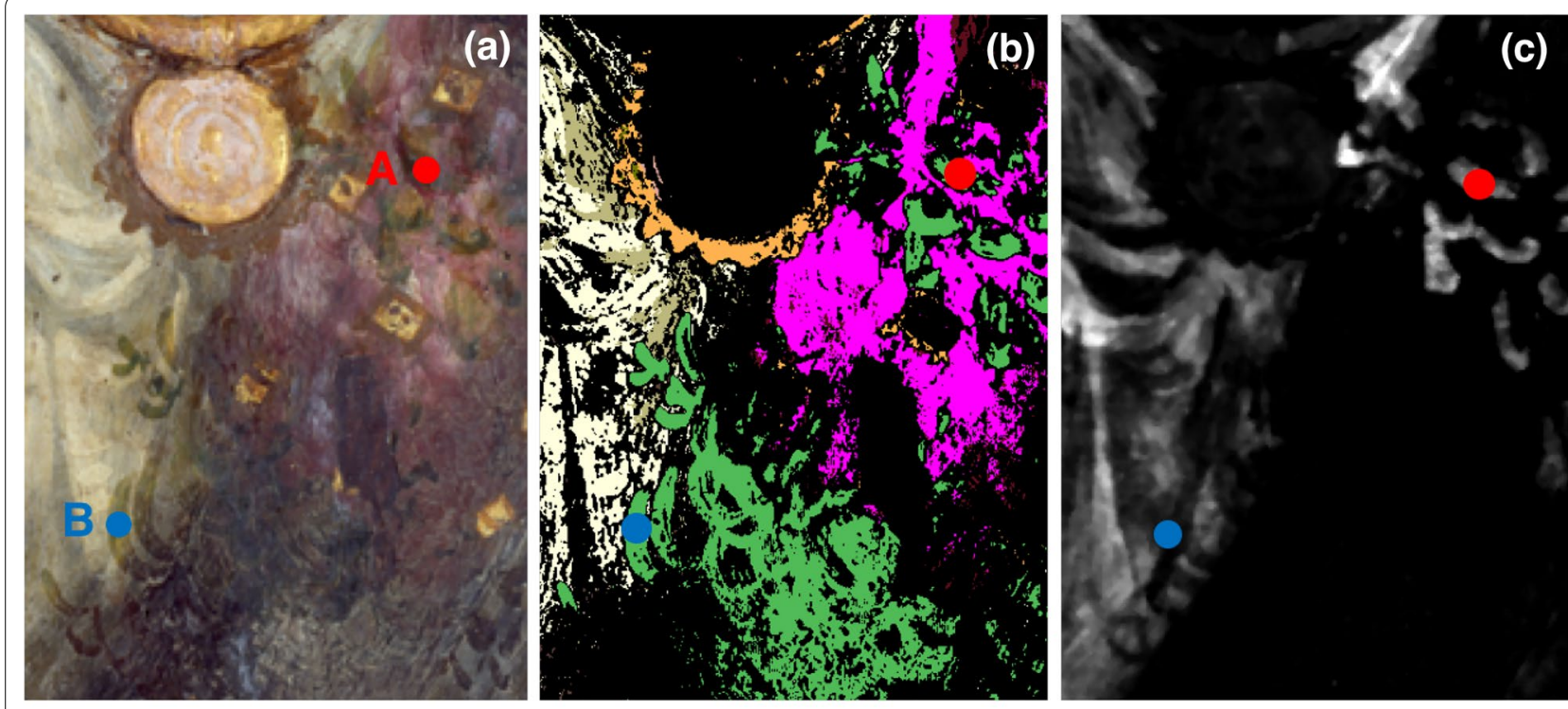

Green pigment - reflectance profiles
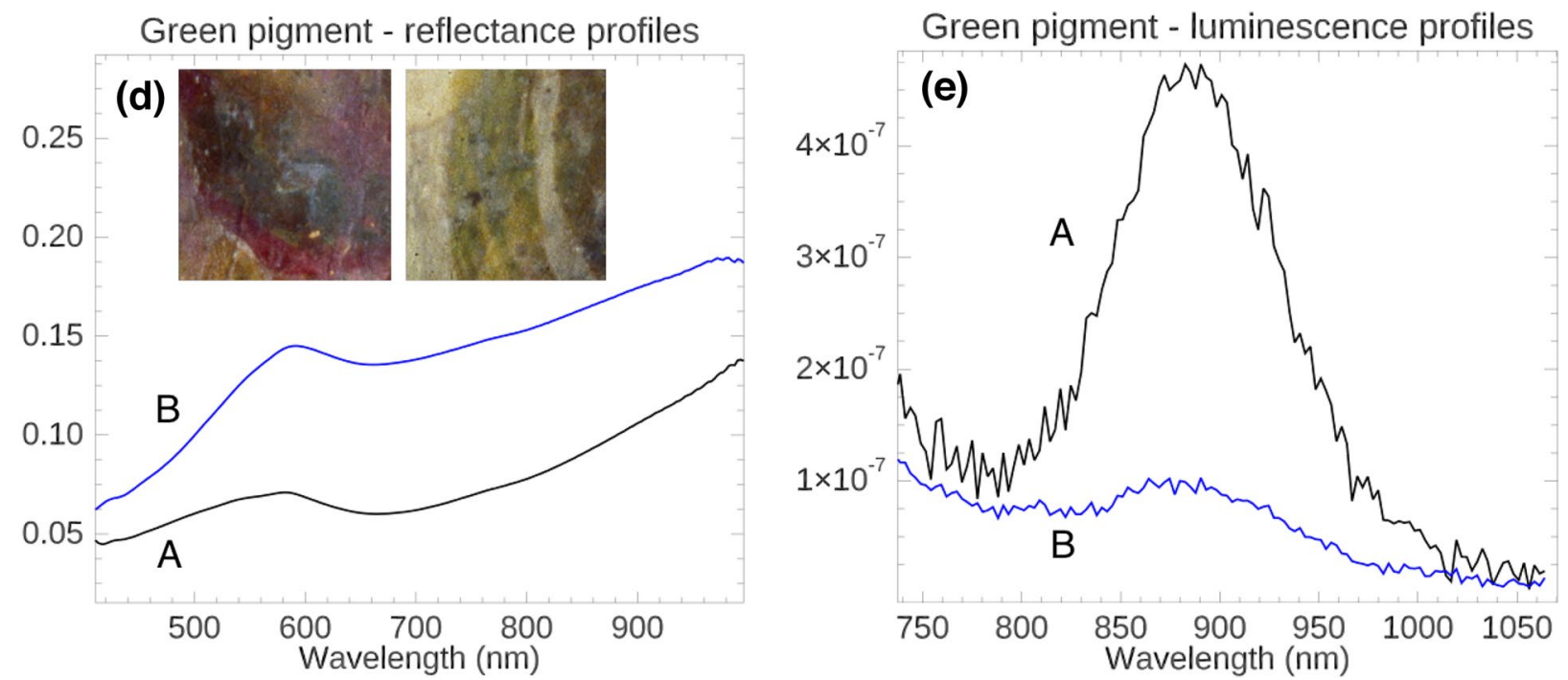

Fig. 7 Close-up of the regions containing the green leaves in the color image (a), RIS SAM map (b) and LIS abundance map (c). Two pixels from the green leaves were selected for comparison, one from over the pink-purple garment (A, corresponding to the red dot) and the other over the white garments ( $B$, corresponding to the blue dot). Their reflectance signatures in $\mathbf{d}$ show the presence of the copper carboxylate pigment. The luminescence emission from A confirms that Egyptian blue was applied with the green pigment, perhaps to offer a blue-ish tone, as seen in the left inset in $\mathbf{d}$. The luminescence emission from B is extremely weak and most likely captured from the white pigment below the green leaf, as the green application here is thin and seemingly semi-transparent (right inset in $\mathbf{d}$ )

also cause weaker emission signals to be blue-shifted. LIS presents another advantage over single-band imaging in that the presence of stray light can be distinguished and addressed, even qualitatively, to improve chemical mapping and interpretation of datasets. The RIS and LIS data also helped assign the red lake in this painting as plant based. The double-structured absorptions at 514 and 547 $\mathrm{nm}$ and the strong fluorescence emission is characteristic of a purpurin-rich madder lake (likely sourced from the wild Rubia Peregrina [79]), while absorptions at $\sim 525$ and $565 \mathrm{~nm}$ would have identified an insect-based lake [58]. The use of purpurin-rich red lake, however, is prevalent in ancient painting and polychromy.

The chemical analysis and resultant maps of the painting highlights interesting artistic choices and trends, both in the context of Roman Egyptian funerary portraits, and also looking at paintings discovered in the broader ancient Mediterranean [80]. Madder lake in the pink-purple garment is consistent with the finds of other funerary portraits where madder lake was used to paint 
the women's garments $[25,47,81]$. This also has real-life connection to practices in ancient society where madder was used for dyeing garments and clavi [82-84]. LIS also helped to emphasize the application of madder lake to the earrings. The fluorescence is quite pronounced and having attention directed to this use in the jewelry allows researchers to begin exploring similar patterns in other portraits to fill in knowledge gaps about artists' techniques and decision-making in Roman Egyptian painting. Imaging spectroscopy provides great potential to explore and compare material and artistic trends of important portraits in other collections with similar stylistic execution and point of origin, such as those in the Louvre Museum and the Detroit Institute of Arts [50, 85, 86].

A presently open question but important to note is the appearance of a soft white haze on the surface of the portrait. Over her face and around the top of the woman's head, the white haze, not attributed to the same lead white pigment used for the bulk of her veil and her garments, is a possible manifestation of an alteration process. As the binding media is wax-based, it is highly possible for a form of saponification or other degradation process to have occurred to induce the formation of metal carboxylates or saturated fatty acids on the surface. Ongoing studies on ancient encaustic painting and saponification processes may help with further insight on the cause for this haze [87]. Microanalyses via sampling can provide a better assignment on this surface material.

We also note the possibility of other transformations ongoing in the portrait, specifically in the lead white pigment, which we assigned through elemental characterization. The absence of the $\mathrm{OH}$ stretching feature of hydrocerussite at $1449 \mathrm{~nm}$ in the FORS spectra prompts additional questions about potential transformation of hydrocerussite in encaustic painting applications and the loss of the hydration signature. A recent study on the alteration of lead white in historical polychrome sculpture showed the presence of lead chlorides, a degradation by-product [88]. This should encourage further inquiry into potential alteration products associated with this pigment in ancient painting, as well as development of novel non-invasive approaches to identify such products.

\section{Conclusion}

In this research, imaging spectroscopy was applied in both reflectance and luminescence imaging modes to characterize and interpret the painting materials and artistic choices implemented in a Roman Egyptian funerary portrait. The data analysis approach utilized derivative analyses to enhance discrimination between different pigment applications and access low emission signals from photoluminescence. While madder lake has been previously identified in ancient painting using LIS, this study demonstrates how robust chemical mapping using imaging spectroscopy can also identify and visualize Egyptian blue at the macroscale. Compared to conventional imaging approaches with a modified DSLR camera, LIS provides a powerful alternative for mapping of the pigment by relying on measurement of chemical properties versus capture of "unlabeled" luminescence.

It must be emphasized that while imaging spectroscopy provides rich image cubes and valuable modes of characterization for macroscale analyses, it is not possible to interpret the entire complexity of these intricate paintings. The objective is to determine primary pigments and mixtures used to achieve the lifelike portraits. Furthermore, the resultant maps give researchers a glimpse into ancient Roman Egyptian society by identifying painting material use that reflects real life practices, evidence of painting trends and knowledge of the chemical arts as well as providing scientific validation of artists' practices described in ancient texts.

\begin{abstract}
Acknowledgements
The authors thank and acknowledge support from the Walters Art Museum and the National Gallery of Art, Washington D.C. The authors also thank Dr. Lisa Anderson-Zhu, associate curator of Ancient Mediterranean Art at the Walters Art Museum, for her insightful feedback on the portrait's discussion and interpretation.
\end{abstract}

\section{Authors' contributions}

Data collection: RR, GAG, JKD; data analysis: RR, GAG, and JKD; writing — draft preparation: RR; writing — review and editing RR, GAG, JKD, IK. All authors read and approved the final manuscript.

\section{Funding}

The authors have no funding to declare for this work.

\section{Availability of data and materials}

The datasets used and/or analyzed during the current study are available from the corresponding author upon reasonable request.

\section{Declarations}

Competing interests

The authors declare that they have no competing interests.

\section{Author details}

${ }^{1}$ Materials Science \& Engineering, University of California, Los Angeles, Los Angeles, USA. ${ }^{2}$ Department of Conservation and Technical Research, Walters Art Museum, Baltimore, USA. ${ }^{3}$ Scientific Research Department, National Gallery of Art, Washington, DC, USA.

Received: 20 September 2021 Accepted: 24 December 2021 Published online: 15 January 2022

References

1. Laurie AP. The painter's methods and materials. New York: Dover Publications; 1967.

2. Barnett JR, Miller S, Pearce E. Colour and art: a brief history of pigments. Opt Laser Technol. 2006;38(4):445-53. https://doi.org/10.1016/j.optlastec. 2005.06.005.

3. Heilmeyer WD. Ancient workshops and ancient 'art'. Oxford J Archaeol. 2004;23(4):403-15. 
4. Lucas A, Harris J. Ancient Egyptian materials and industries. New York: Dover Publications; 2012.

5. Craddock P. Mining and smelting in antiquity. Science and the Past, University of Toronto Press, pp. 57--73 2016.

6. Forbes RJ. Studies in ancient technology, vol. 8. 2nd ed. Leiden: Brill; 1971.

7. Brecoulaki H. "Pecious colours" in ancient Greek polychromy and painting: material aspects and symbolic values. Revue archéologique. 2014;1:3-35.

8. Scott DA. A review of ancient Egyptian pigments and cosmetics. Stud Conserv. 2016:61(4):185-202.

9. Thieme C. Paint layers and pigments on the terracotta army: a comparison with other cultures of antiquity. Monum Sites. 2001;3:52-8.

10. Kakoulli I. Greek painting techniques and materials from the fourth to the first century BC. London: Archetype Publ.; 2009.

11. Cucci C, Delaney JK, Picollo M. Reflectance hyperspectral imaging for investigation of works of art: old master paintings and illuminated manuscripts. Acc Chem Res. 2016;49(10):2070-9.

12. Ricciardi P, Delaney JK, Glinsman L, Thoury M, Facini M, de la Rie ER. Use of visible and infrared reflectance and luminescence imaging spectroscopy to study illuminated manuscripts: pigment identification and visualization of underdrawings. In: 3A: optics for arts, architecture, and archaeology II, vol. 7391. International Society for Optics and Photonics; 2009. p. 739106.

13. Dooley KA, Conover DM, Glinsman LD, Delaney JK. Complementary standoff chemical imaging to map and identify artist materials in an early Italian Renaissance panel painting. Angew Chem Int Ed. 2014;53(50):13775-9.

14. Daniel F, Mounier A, Pérez-Arantegui J, Pardos C, Prieto-Taboada N, de Vallejuelo SF-O, Castro K. Hyperspectral imaging applied to the analysis of Goya paintings in the Museum of Zaragoza (Spain). Microchem J. 2016;126:113-20.

15. Delaney JK, Thoury M, Zeibel JG, Ricciardi P, Morales KM, Dooley KA. Visible and infrared imaging spectroscopy of paintings and improved reflectography. Herit Sci. 2016;4(1):6.

16. Delaney JK, Zeibel JG, Thoury M, Littleton R, Palmer M, Morales KM, de La Rie ER, Hoenigswald A. Visible and infrared imaging spectroscopy of Picasso's Harlequin Musician: mapping and identification of artist materials in situ. Appl Spectrosc. 2010;64(6):584-94.

17. Siddall R. Mineral pigments in archaeology: their analysis and the range of available materials. Minerals. 2018;8(5):201.

18. Orna MV. Historic mineral pigments: colorful benchmarks of ancient civilizations. In: Chemical technology in antiquity. Washington: American Chemical Society; 2015. p. 17-69.

19. Kakoulli I. Late classical and Hellenistic painting techniques and materials: a review of the technical literature. Stud Conserv. 2002;47(sup1):56-67.

20. Jaksch H, Seipel W, Weiner K-L, El Goresy A. Egyptian blue-Cuprorivaite a window to ancient Egyptian technology. Naturwissenschaften. 1983;70(11):525-35.

21. Berke $H$. The invention of blue and purple pigments in ancient times. Chem Soc Rev. 2007;36(1):15-30.

22. Daniels V, Deviese T, Hacke M, Higgitt C. Technological insights into madder pigment production in antiquity. In: British museum technical research bulletin, vol. 8. 2014. p. 13-28. https://hal-amu.archives-ouvertes. $\mathrm{fr} /$ hal-03207945.

23. Melo MJ. History of natural dyes in the ancient Mediterranean world. In: Handbook of natural colorants. Chichester: Wiley; 2009. p. 3-20.

24. Welcomme E, Walter P, Van Elslande E, Tsoucaris G. Investigation of white pigments used as make-up during the Greco-Roman period. Appl Phys A. 2006;83(4):551-6.

25. Salvant J, Williams J, Ganio M, Casadio F, Daher C, Sutherland K, Monico L, Vanmeert F, De Meyer S, Janssens K, Cartwright C, Walton M. A Roman Egyptian painting workshop: technical investigation of the portraits from Tebtunis, Egypt. Archaeometry. 2018;60(4):815-33. https://doi.org/10. 1111/arcm.12351.

26. Radpour R, Fischer C, Kakoulli I. New insight into Hellenistic and Roman Cypriot wall paintings: an exploration of artists' materials, production technology, and technical style. Arts. 2019. https://doi.org/10.3390/arts8 020074.

27. Gettens RJ, Kühn H, Chase WT. Lead white. Stud Conserv. 1967;12(4):125-39.
28. Eichholz DE. Pliny: natural history, vol. IX: books XXXIII-XXXV. With an English translation by H. Rackham. (Loeb Classical Library). Class Rev. 1954:4(2):136-8.

29. Caley ER, Richards JF. Theophrastus: on stones. Introduction, Greek text, English translation, and commentary by Caley and Richards. Columbus: The Ohio State University Press; 1956.

30. Kakoulli I, Fischer C, Michaelides D. Painted rock-cut tombs in Cyprus from the Hellenistic and Roman periods to Byzantium: material properties, degradation processes and sustainable preservation strategies. Stud Conserv. 2010;55(sup2):96-102.

31. Accorsi G, Verri G, Bolognesi M, Armaroli N, Clementi C, Miliani C, Romani A. The exceptional near-infrared luminescence properties of cuprorivaite (Egyptian blue). Chem Commun. 2009;23:3392-4.

32. Verri G. The application of visible-induced luminescence imaging to the examination of museum objects. In: O3A: optics for arts, architecture, and archaeology II, vol. 7391. International Society for Optics and Photonics; 2009. p. 739105.

33. Verri G, Saunders D, Ambers J, Sweek T. Digital mapping of Egyptian blue: conservation implications. Stud Conserv. 2010;55(sup2):220-4. https:// doi.org/10.1179/sic.2010.55.Supplement-2.220

34. Fostiridou A, Karapanagiotis I, Vivdenko S, Lampakis D, Mantzouris D, Achilara L, Manoudis P. Identification of pigments in Hellenistic and Roman funeral figurines. Archaeometry. 2016;58(3):453-64.

35. Colombini MP, Carmignani A, Modugno F, Frezzato F, Olchini A, Brecoulaki $\mathrm{H}$, Vassilopoulou V, Karkanas P. Integrated analytical techniques for the study of ancient Greek polychromy. Talanta. 2004;63(4):839-48.

36. Clementi C, Doherty B, Gentili PL, Miliani C, Romani A, Brunetti BG, Sgamellotti A. Vibrational and electronic properties of painting lakes. Appl Phys A. 2008;92(1):25-33.

37. Grazia C, Clementi C, Miliani C, Romani A. Photophysical properties of alizarin and purpurin $\mathrm{Al}(\mathrm{III})$ complexes in solution and in solid state. Photochem Photobiol Sci. 2011;10(7):1249-54.

38. Kakoulli I, Radpour R, Lin Y, Svoboda M, Fischer C. Application of forensic photography for the detection and mapping of Egyptian blue and madder lake in Hellenistic polychrome terracottas based on their photophysical properties. Dyes Pigments. 2017;136:104-15.

39. Shaw GA, Burke H-HK. Spectral imaging for remote sensing. Lincoln Lab J 2003;14(1):3-28.

40. Plaza A, Benediktsson JA, Boardman JW, Brazile J, Bruzzone L, CampsValls G, Chanussot J, Fauvel M, Gamba P, Gualtieri A, Marconcini M, Tilton JC, Trianni G. Recent advances in techniques for hyperspectral image processing. Remote Sens Environ. 2009;113:110-22. https://doi.org/10. 1016/j.rse.2007.07.028.

41. Liang H, Lucian A, Lange $R$, Cheung CS, Su B. Remote spectral imaging with simultaneous extraction of 3D topography for historical wall paintings. ISPRS J Photogramm Remote Sens. 2014;95:13-22. https://doi.org/ 10.1016/j.isprsjprs.2014.05.011.

42. Alfeld M, Pedetti S, Martinez P, Walter P. Joint data treatment for Vis-NIR reflectance imaging spectroscopy and XRF imaging acquired in the Theban Necropolis in Egypt by data fusion and t-SNE. Comptes Rendus Physique. 2018;19(7):625-35.

43. Alfeld M, Mulliez M, Devogelaere J, De Viguerie L, Jockey P, Walter P. MA-XRF and hyperspectral reflectance imaging for visualizing traces of antique polychromy on the frieze of the Siphnian Treasury. Microchem J. 2018;141:395-403.

44. Sun M, Zhang D, Wang Z, Ren J, Chai B, Sun J. What's wrong with the murals at the Mogao Grottoes: a near-infrared hyperspectral imaging method. Sci Rep. 2015;5:1-10.

45. Dooley KA, Chieli A, Romani A, Legrand S, Miliani C, Janssens K, Delaney JK. Molecular fluorescence imaging spectroscopy for mapping low concentrations of red lake pigments: Van Gogh's painting The Olive Orchard. Angew Chem. 2020;132(15):6102-9.

46. Clementi C, Miliani C, Verri G, Sotiropoulou S, Romani A, Brunetti BG, Sgamellotti A. Application of the Kubelka-Munk correction for selfabsorption of fluorescence emission in Carmine lake paint layers. Appl Spectrosc. 2009:63(12):1323-30.

47. Delaney JK, Dooley KA, Radpour R, Kakoulli I. Macroscale multimodal imaging reveals ancient painting production technology and the vogue in Greco-Roman Egypt. Sci Rep. 2017;7(1):15509. https://doi.org/10.1038/ s41598-017-15743-5. 
48. Dyer J, Verri G, Cupitt J. Multispectral imaging in reflectance and photo-induced luminscence modes: a user manual. London: The British Museum; 2013.

49. Gabrieli F, Dooley KA, Facini M, Delaney JK. Near-UV to mid-IR reflectance imaging spectroscopy of paintings on the macroscale. Sci Adv. 2019. https://doi.org/10.1126/sciadv.aaw7794.

50. Doxiadis E. the mysterious fayum portraits: faces from ancient Egypt. Cairo: The American University in Cairo Press; 1995.

51. Borg BE. Painted funerary portraits. 2010.

52. Walters EJ. Attic grave reliefs that represent women in the dress of Isis. American School of Classical Studies at Athens: Princeton; 1988. p. 22.

53. Wiedenhoeft AC. Wood specimen analysis. United States Department of Agriculture

54. Conover DM, Delaney JK, Loew MH. Automatic registration and mosaicking of technical images of old master paintings. Appl Phys A. 2015;119(4):1567-75.

55. Lagorio MG, Dicelio LE, Litter MI, San Román E. Modeling of fluorescence quantum yields of supported dyes aluminium carboxyphthalocyanine on cellulose. J Chem Soc Faraday Trans. 1998;94:419-25. https://doi.org/10. 1039/A706113G.

56. Tsai F, Philpot W. Derivative analysis of hyperspectral data. Remote Sens Environ. 1998:66(1):41-51.

57. Bacci M, Picollo M, Trumpy G, Tsukada M, Kunzelman D. Non-invasive identification of white pigments on 20th-century oil paintings by using fiber optic reflectance spectroscopy. J Am Inst Conserv. 2007;46(1):27-37.

58. Aceto M, Agostino A, Fenoglio G, Idone A, Gulmini M, Picollo M, Ricciardi $P$, Delaney JK. Characterisation of colourants on illuminated manuscripts by portable fibre optic UV-visible-NIR reflectance spectrophotometry. Anal Methods. 2014;6(5):1488-500.

59. Boardman JW. Analysis, understanding, and visualization of hyperspectral data as convex sets in n space. In: Imaging spectrometry, vol. 2480. International Society for Optics and Photonics; 1995. p. 14-22.

60. Gruninger $\mathrm{JH}$, Ratkowski AJ, Hoke ML. The sequential maximum angle convex cone (SMACC) endmember model. In: Algorithms and technologies for multispectral, hyperspectral, and ultraspectral imagery $X$, vol. 5425. International Society for Optics and Photonics; 2004. p. 1-14.

61. Keshava N, Mustard JF. Spectral unmixing. IEEE Signal Process Mag. 2002;19(1):44-57.

62. Torrent J, Barrón V. Diffuse reflectance spectroscopy of iron oxides. Encycl Surf Colloid Sci. 2002;1:1438-46.

63. Sherman DM, Burns RG, Burns VM. Spectral characteristics of the iron oxides with application to the Martian bright region mineralogy. J Geophys Res Solid Earth. 1982;87(B12):10169-80.

64. Gonzalez V, Gourier D, Calligaro T, Toussaint K, Wallez G, Menu M. Revealing the origin and history of lead-white pigments by their photoluminescence properties. Anal Chem. 2017;89(5):2909-18.

65. Hunt GR. Visible and near-infrared spectra of minerals and rocks: I silicate minerals. Modern Geol. 1970;1:283-300.

66. Delaney JK, Dooley KA, Van Loon A, Vandivere A. Mapping the pigment distribution of Vermeer's Girl with a Pearl Earring. Herit Sci. 2020;8(1):1-16.

67. Cloutis EA, Hawthorne FC, Mertzman SA, Krenn K, Craig MA, Marcino D, Methot M, Strong J, Mustard JF, Blaney DL, Bell JF, Vilas F. Detection and discrimination of sulfate minerals using reflectance spectroscopy. Icarus. 2006;184(1):121-57. https://doi.org/10.1016/j.icarus.2006.04.003.

68. Cloutis E, Norman L, Cuddy M, Mann P. Spectral reflectance (350-2500 $\mathrm{nm}$ ) properties of historic artists' pigments. II. Red-orange-yellow chromates, jarosites, organics, lead (-tin) oxides, sulphides, nitrites and antimonates. J Near Infrared Spectrosc. 2016;24(2):119-40.

69. Shannon RD. Revised effective ionic radii and systematic studies of interatomic distances in halides and chalcogenides. Acta Crystallogr Sect A Crystal Phys Diffr Theor Gen Crystallogr. 1976;32(5):751-67.

70. Dooley KA, Lomax S, Zeibel JG, Miliani C, Ricciardi P, Hoenigswald A, Loew M, Delaney JK. Mapping of egg yolk and animal skin glue paint binders in Early Renaissance paintings using near infrared reflectance imaging spectroscopy. Analyst. 2013;138(17):4838-48.

71. Osborne BG, Fearn T, Hindle PH, et al. Practical NIR spectroscopy with applications in food and beverage analysis. Harlow: Longman Scientific \& Technical; 1993.

72. Sohn M, Himmelsbach DS, Morrison WH, Akin DE, Barton FE. Partial least squares regression calibration for determining wax content in processed flax fiber by near-infrared spectroscopy. Appl Spectrosc. 2006;60(4):437-40.

73. Kakoulli I, Fischer C. The Techniques and materials of the wall paintings at the Enkleistra of St. Neophytos (phase II). Dumbarton Oaks Report (2011-2012).

74. Mazurek J, Svoboda M, Schilling M. GC/MS characterization of beeswax protein, gum, resin, and oil in Romano-Egyptian paintings. Heritage. 2019;2(3):1960-85.

75. Ganio M, Salvant J, Williams J, Lee L, Cossairt O, Walton M. Investigating the use of Egyptian blue in Roman Egyptian portraits and panels from Tebtunis, Egypt. Appl Phys A. 2015;121(3):813-21.

76. Radpour R, Lin Y, Svoboda M, Chiari G, Fischer C, Kakoulli I. Materials characterization of Greco-Roman mummy portraits using forensic photography and noninvasive spectroscopy. Presented at Technart 2017, May 3, 2017. Spain: Bilbao; 2017.

77. Brecoulaki H, Sotiropoulou S, Katsifas C, Karydas AG. A microcosm of colour and shine. The polychromy of chryselephantine couches from ancient Macedonia. Technè: la science au service de l'histoire de l'art et des civilisations. 2014;(40):9.

78. Daniels $\vee$. Analyses of copper- and beeswax-containing green paint on Egyptian antiquities. Stud Conserv. 2007;52(1):13-8.

79. Aceto M. Pigments - the palette of organic colourants in wall paintings. Archaeol Anthropol Sci. 2021;13(10):1-23.

80. Svoboda M, Cartwright C. Mummy portraits of Roman Egypt: emerging research from the APPEAR project. 2020; Los Angeles: Getty Publications.

81. The APPEAR (ancient panel paintings: examination, analysis, and research) project, the J. Paul Getty Museum. https://www.getty.edu/ museum/research/appear_project/.

82. Szostek B, Orska-Gawrys J, Surowiec I, Trojanowicz M. Investigation of natural dyes occurring in historical Coptic textiles by high-performance liquid chromatography with UV-Vis and mass spectrometric detection. J Chromatogr A. 2003;1012(2):179-92.

83. Caley ER. The Stockholm Papyrus. An English translation with brief notes. J Chem Educ. 1927;4(8):979. https://doi.org/10.1021/ed004p979.

84. Karapanagiotis I, Verhecken-Lammens C, Kamaterou P. Identification of dyes in Egyptian textiles of the first millennium AD from the collection fill-trevisiol. Archaeol Anthropol Sci. 2019;11(6):2699-710.

85. Mummy portrait, the Louvre Museum. https://collections.louvre.fr/en/ ark:/53355/cl010451181.

86. Head of a woman, The Detroit Institute of Arts. https://www.dia.org/art/ collection/object/head-woman-43487.

87. Stacey RJ, Dyer J, Mussell C, Lluveras-Tenorio A, Colombini M, Duce C, La Nasa J, Cantisani E, Prati S, Sciutto G, et al. Ancient encaustic: an experimental exploration of technology, ageing behaviour and approaches to analytical investigation. Microchem J. 2018;138:472-87.

88. Ma X, Berrie BH. Lead chlorides in paint on a della Robbia terracotta sculpture. Anal Chem. 2020;92(7):4935-42.

\section{Publisher's Note}

Springer Nature remains neutral with regard to jurisdictional claims in published maps and institutional affiliations.

\section{Submit your manuscript to a SpringerOpen ${ }^{\circ}$ journal and benefit from:}

- Convenient online submission

- Rigorous peer review

- Open access: articles freely available online

- High visibility within the field

- Retaining the copyright to your article

Submit your next manuscript at springeropen.com 